\title{
PARAMETER ANALYSIS AND OPTIMIZATION OF THE ROTATING ARC NG-GMAW WELDING PROCESS
}

\author{
Duan, B.; Wang, J. C.; Lu, Z. H.; Zhang, G. X. \& Zhang, C. H.\# \\ Shandong University, Shandong Province, China \\ E-Mail: duanbin@sdu.edu.cn, zchui@sdu.edu.cn (" Corresponding author)
}

\begin{abstract}
Parameters of the narrow gap gas metal arc welding (NG-GMAW) method are complex and strongly coupled, which can easily cause welding defects, such as poor sidewall fusion, overlap, gas pore and slag inclusion. So parameter optimization of NG-GMAW is very difficult. The common experimental analysis method is complex, especially take a long time and cost. In this paper, the simulation analysis method is used to analyse NG-GMAW welding process. After the analysis of the NG-GMAW welding mechanism, the dynamic simulation model of the rotating arc NG-GMAW welding process is established firstly. Then, the influence of key process parameters on the welding quality is analysed in detail, which include the rotation angular velocity, rotation angular amplitude, wire feed speed, welding speed, sidewall stay time and so on. The simulation and analysis results illustrate the role and influence of the above parameters. In short, this paper provides a flexible and efficient method for the analysis and optimization of NG-GMAW welding process parameters to discover new phenomena, improve efficiency and save cost.

(Received, processed and accepted by the Chinese Representative Office.)
\end{abstract}

Key Words: NG-GMAW, Rotating Arc, Simulation Model, Parameters Optimization

\section{INTRODUCTION}

With the rapid development of modern manufacturing industry, especially the large demand of thick and ultra-thick plates in the ultra-high speed, supercritical and other extreme service environment, it is extremely urgent to research and develop high-efficient welding technology and high-performance welding equipment $[1,2]$. The narrow gap welding method is known for saving time, electricity and material, which has the great application prospect in modern industrial and military fields, such as the high pressure vessels, ships, deep sea detectors and spacecrafts [3].

Compared with traditional welding methods, the narrow gap welding method has advantages of high-efficient and energy-saving especially for more than $30 \mathrm{~mm}$ thick plates by reducing the cross section of grooves and using medium or small energy input. Compared with the submerged arc welding (SAW), the narrow gap gas metal arc welding (NG-GMAW) method can save more than half of the welding material and increase nearly 2.5 times of the welding productivity. Moreover, the welding energy input can be controlled easily to realize all directions of welding $[4,5]$.

However, the factors that affect the NG-GMAW welding process are complex and strongly coupled, leading to poor fusion of the sidewalls and other welding quality problems [6-8]. The experimental analysis method to optimize the process parameters is complex, especially take a long time and cost [9-10]. The simulation analysis method is particularly suitable for the NG-GMAW, which can improve efficiency and save cost. So first, the mathematical model of the rotating arc NG-GMAW welding process is established in this paper. Then, the influence of key process parameters on the welding quality is analysed in detail. Finally, selection rules of the NG-GMAW welding process parameters are given. 


\section{NG-GMAW WELDING PROCESS MODELLING}

\subsection{Analysis of the rotating arc NG-GMAW welding process}

The schematic diagram of the rotating arc NG-GMAW is shown in Fig. 1 [11], where the curved tip drives the arc back and forth rotation. In the welding process, parameters such as sidewall stay time, rotation angular velocity, and amplitude, must be matched reasonably to realize high quality sidewall fusion and weld formation. Because the radius of arc rotation is not constrained by the tip, it is theoretically possible to weld any thickness of the plate as shown in Fig. 2.

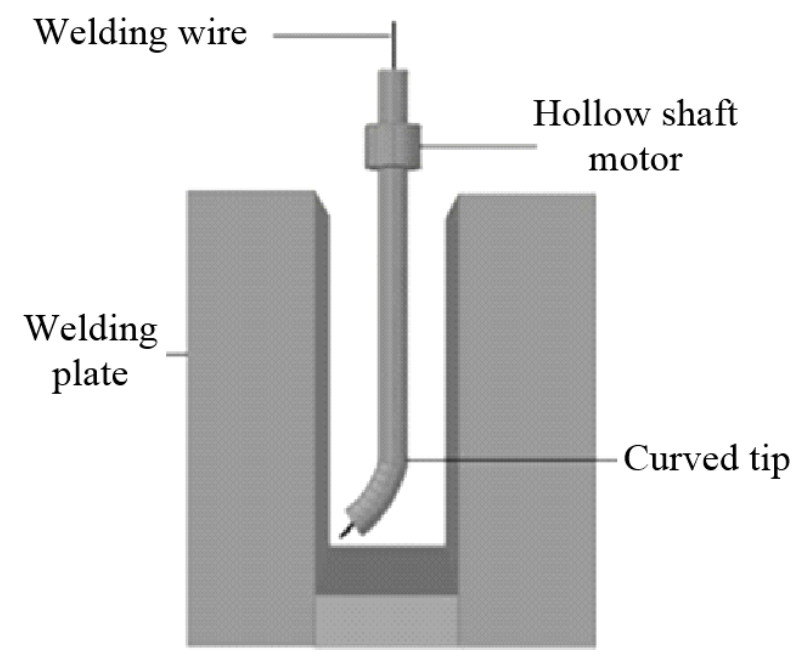

Figure 1: Schematic diagram of the rotating arc NG-GMAW.

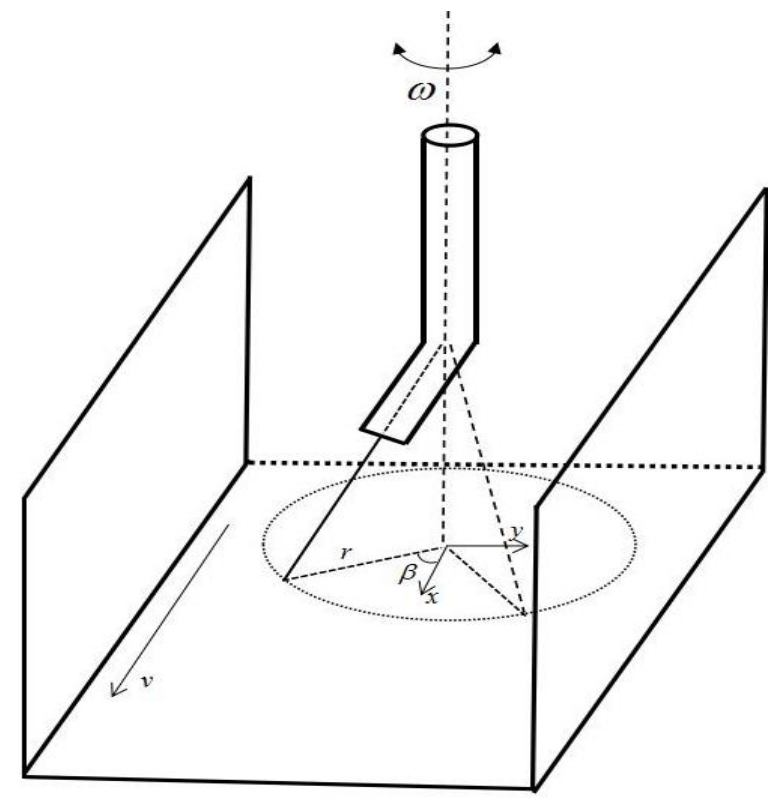

Figure 2: Geometric diagram of the rotating arc NG-GMAW.

In Fig. 2, $\omega$ stands the rotation angular velocity of the welding gun. $r$ is the rotation radius, $\beta$ is the rotation angle, and $v$ is the welding speed, which is a constant. When the welding gun rotates to the sidewall, it will stay for some time $t_{s}$. And at this time, the rotation angular velocity becomes zero, and the sidewall absorbs most of the arc heat to promote the melting of the sidewall plate and the penetration. In the welding process, the welding gun is always perpendicular to the groove bottom and points to the groove centreline like the $x$-axis in Fig. 
2. While the welding gun is moving at a constant speed $v$, rotate at an angular velocity $\omega$. The superposition of the two movements forms the trajectory of the arc.

\subsection{NG-GMAW welding process modelling based on MATLAB}

According to Fig. 2, the arc velocity $v_{a}$ can be obtained by Eq. (1).

$$
\begin{aligned}
& v_{a x}=-|\omega r \sin \theta|+v=-\omega r \sin \theta+v \\
& v_{a y}=-|\omega r \cos \theta|=-\omega r \cos \theta \\
& v_{a}=\sqrt{v_{a x}{ }^{2}+v_{a y}{ }^{2}}=\sqrt{v^{2}+\omega^{2} r^{2}-2 \omega r v \sin \theta}
\end{aligned}
$$

According to the above welding method, $\omega$ shows a periodic change as shown in Fig. 3, which is positive when the welding gun rotates from right to left, negative when rotates from left to right, and zero when stays on the sidewall.

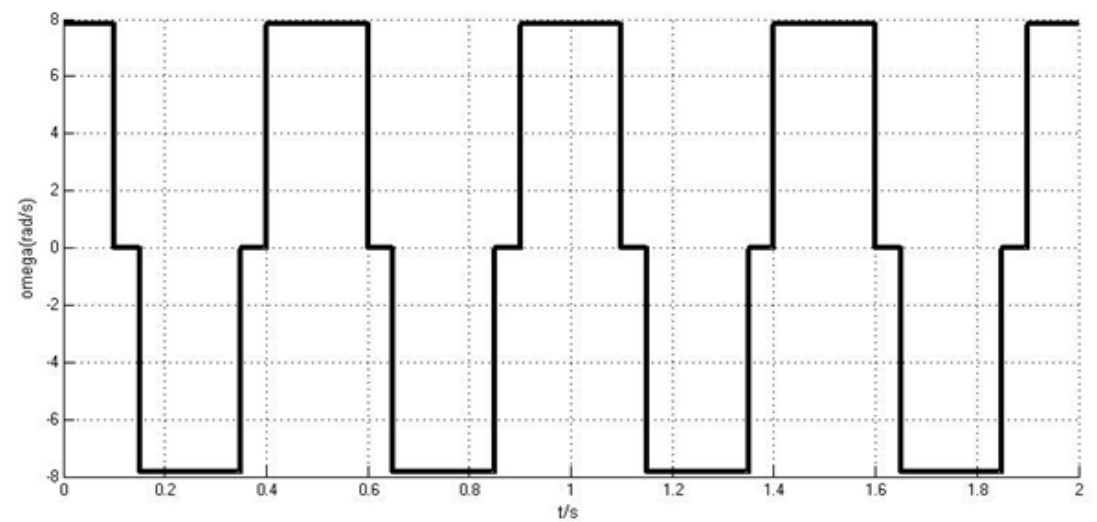

Figure 3: Waveform of $\omega$.

Because the arc rotation angle $\theta$ and $\omega$ have the relationship in Eq. (2), the change waveform of $\theta$ can be obtained as shown in Fig. 4. It's obvious that the periodic change of $\theta$ is the same as that of $\omega$, so whether the welding gun stays on the sidewall can be got by the value of $\theta$.

$$
\theta=\int \omega d t
$$

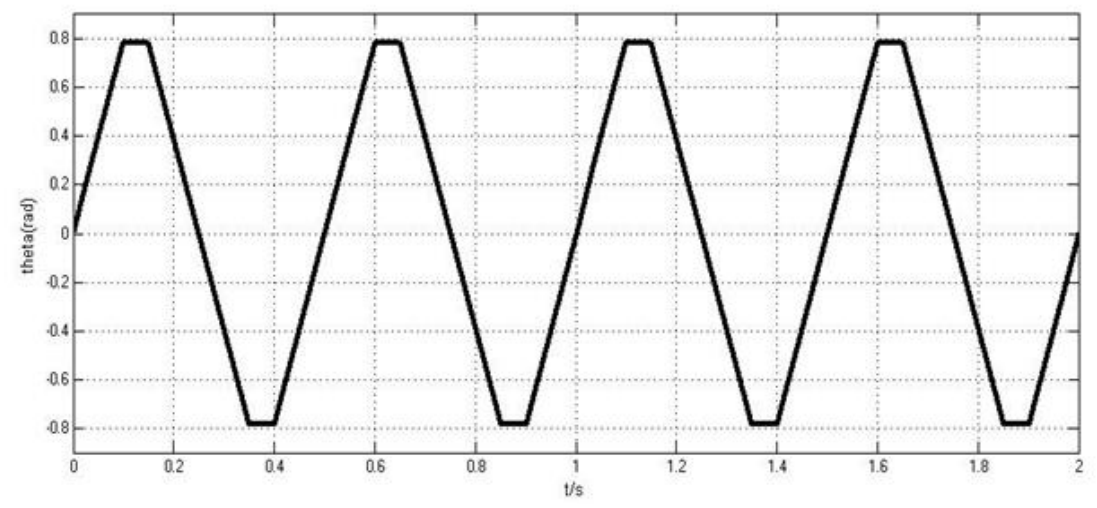

Figure 4: Waveform of $\theta$.

The motion trajectory model of the arc can be established according to Eq. (1) as shown in Fig. 5, where omega and theta are respectively the same with $\omega$ and $\theta$. $v_{a x}$ and $v_{a y}$ are respectively the decomposition speed of $v$ in the $x$-axis and the $y$-axis. And the motion trajectory of the arc is shown in Fig. 6. 


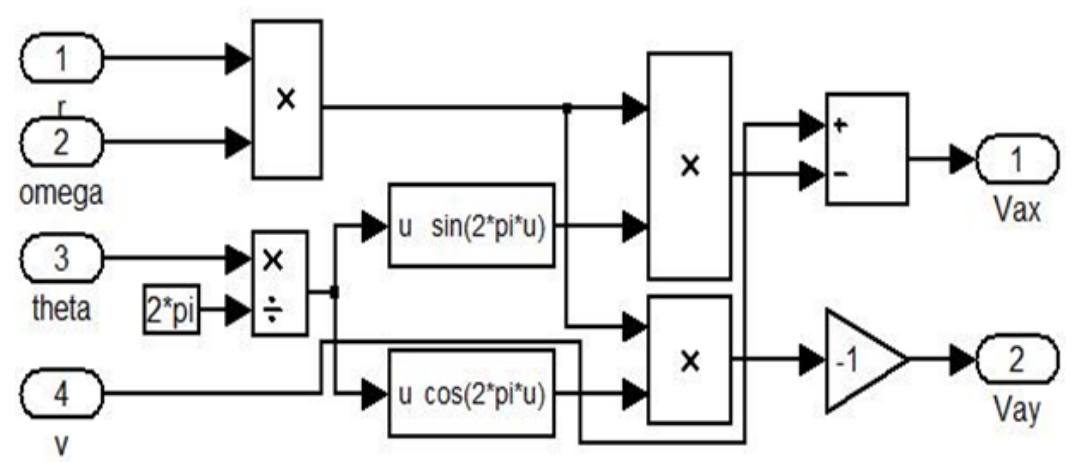

Figure 5: The motion trajectory model of the arc.

With the welding gun reciprocating, the arc swings back and forth to strengthen the pool stirring. When the welding gun stays on the sidewall, most of the heat is distributed to the sidewall to increase the sidewall penetration and keep the sidewall well fused, and the weld bead is a straight line.

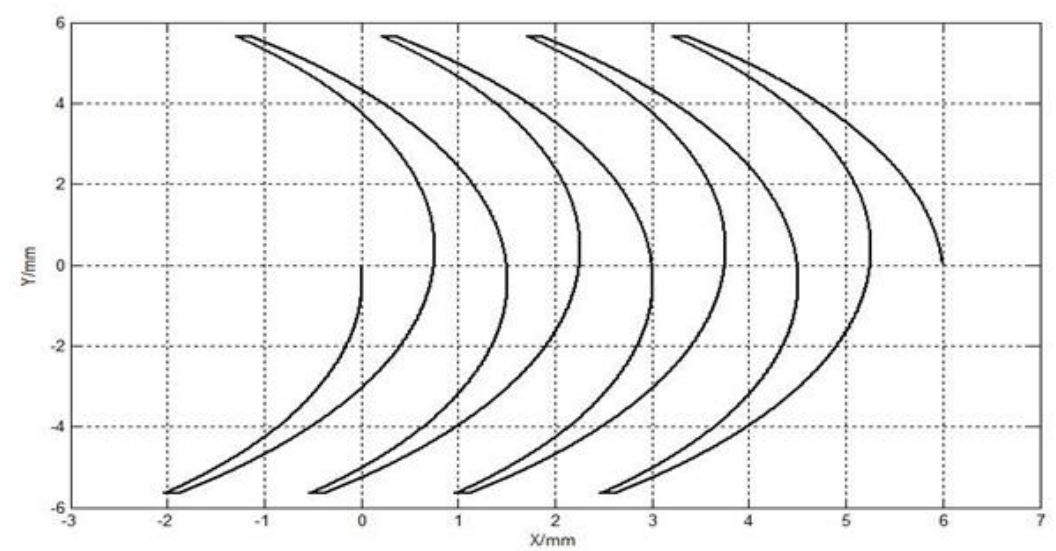

Figure 6: The motion trajectory of the arc.

Since the groove of NG-GMAW is narrow and deep, the heat loss during the welding process is ignored. And then the heat input per unit length $E_{m}$ can be obtained with the welding wire rotation [12-15] as shown in Eq. (3).

$$
E_{m}=\frac{U I}{v_{a}}=\frac{U I}{\sqrt{v^{2}+\omega^{2} r^{2}-2 \omega r v \sin \theta}}
$$

When the welding gun rotates to the sidewall, $\omega$ is zero and the heat input per unit length $E_{e}$ can be obtained as shown in Eq. (4).

$$
E_{e}=\frac{U I}{v_{a}}=\frac{U I}{\sqrt{v^{2}+\omega^{2} r^{2}-2 \omega r v \sin \theta}}=\frac{U I}{v}
$$

According to Eqs. (3) and (4), the welding heat input model can be established as shown in Fig. 7. $U$ is the arc voltage and $I$ is the welding current. The other parameters have the same meaning as the above ones as shown in Fig. 5.

In fact, parameters of the NG-GMAW welding process are very complex, including the groove size, the bending angle of the conductive mouth, the diameter and extension of the welding wire, the arc voltage, the welding current, the welding speed, the rotation speed and many other parameters. So in this paper, the critical parameters that are closely related to the rotating arc and directly affect the welding quality are analysed and discussed. 


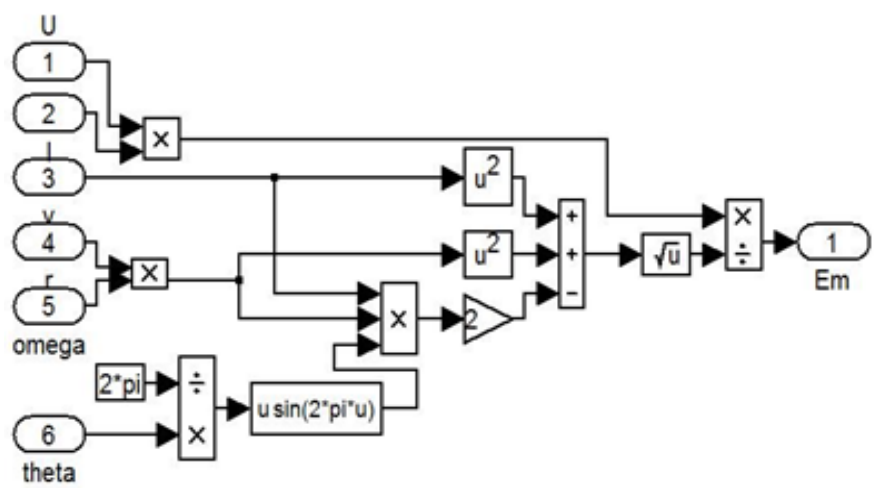

Figure 7: The welding heat input model.

\section{EFFECT OF THE CRITICAL PARAMETERS ON WELDING QUALITY}

\subsection{Effect of the rotation angular velocity and angle}

Assume that $\omega$ increases from $4 \mathrm{rad} / \mathrm{s}$ to $8 \mathrm{rad} / \mathrm{s}$ in 3 seconds, and the rotation amplitude is constant, the simulation result of $E_{m}$ is shown in Fig. 8, and Fig. 9 shows the enlarged waveform on the y-axis of Fig. 8.

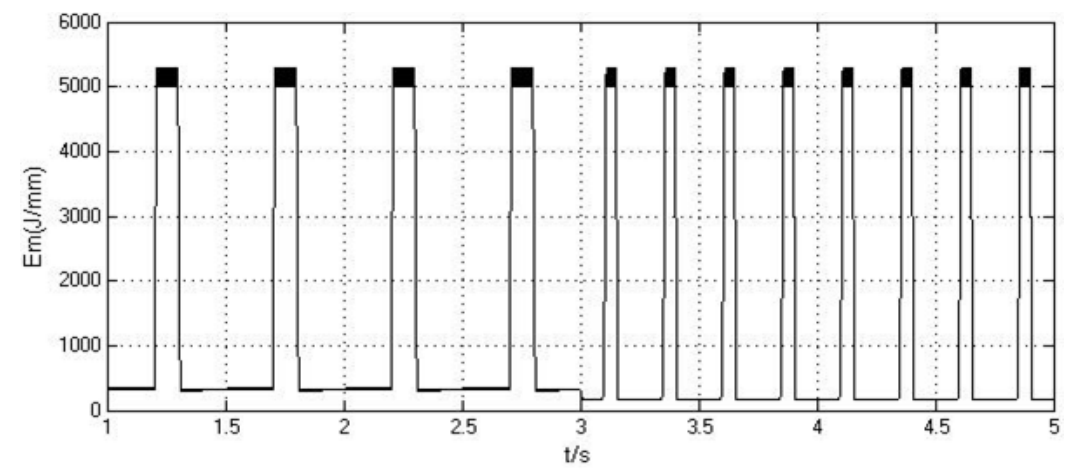

Figure 8: Waveform of $E_{m}$ at different rotation angular velocities.

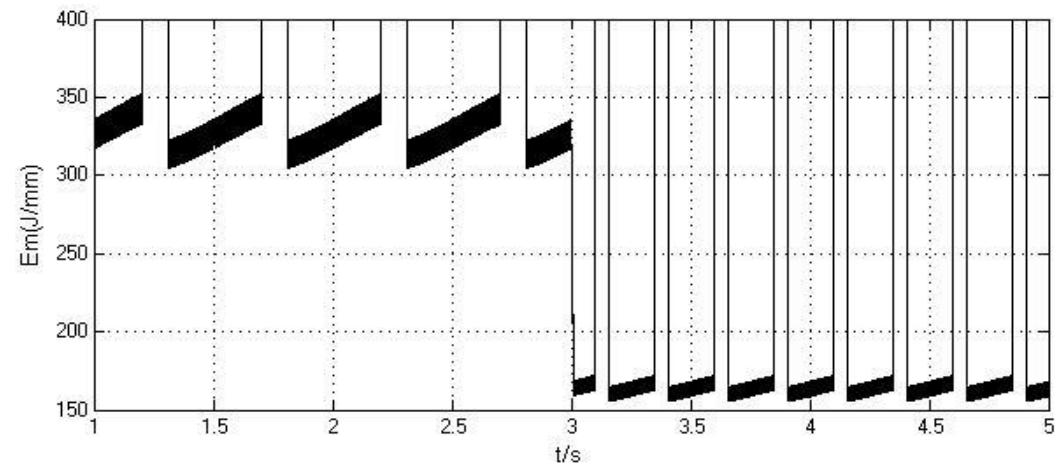

Figure 9: Enlarged waveform of $E_{m}$ in Fig. 8.

It can be seen that $E_{m}$ is vulnerable to $\omega$, and $E_{e}$ is independent of $\omega$. When the welding wire is in the middle of the groove, the heat input obtained by the molten pool decreases and the weld reinforcement is low. As the rotation angle $\beta$ increases, the stirring speed of the pool becomes larger, which will help the weld formation. According to Eq. (3), $E_{m}$ is independent of $\beta$. However, if $\beta$ is too small, the welding wire is in the middle of the groove during the welding gun stays on the sidewall, and the arc cannot cover the entire sidewall, easily leading 
to poor sidewall fusion. Because $E_{e}$ is much larger than $E_{m}$, which is distributed to the middle part of the groove, the arc energy will increase sharply to produce the controllable well weld formation.

\subsection{Effect of the wire feed speed and welding speed}

It can be seen from Fig. 1 that when the welding gun rotates, the distance from the wire tip to the groove bottom is constant. If the wire feed speed is constant, the melting rate is also constant. Besides the arc length and wire extension remains unchanged, then the droplet transfer of the welding process also remains stable. When the wire feed speed is $6 \mathrm{~m} / \mathrm{min}$, the change of $E_{m}$ is approximately the same as the pulse waveform as shown in Fig. 10. The peak and base of the pulse are respectively the sidewall stay stage and the rotation stage of the arc.

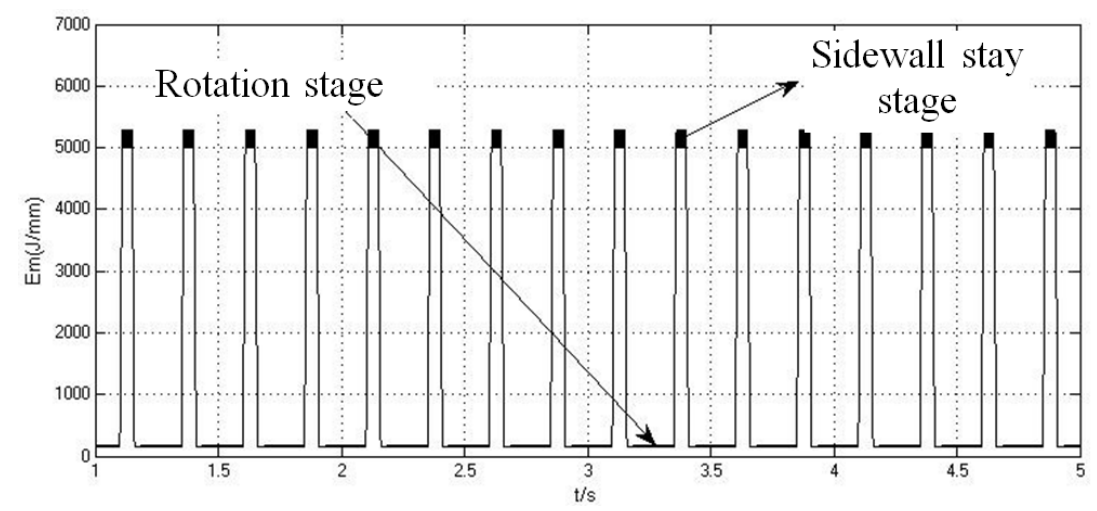

Figure 10: Waveform of $E_{m}$ when the wire feed speed is $6 \mathrm{~m} / \mathrm{min}$.

It can be seen from Fig. 10 that the difference between the peak and base is large. $\omega$ is about $3 \mathrm{rad} / \mathrm{s}$ to $9 \mathrm{rad} / \mathrm{s}, r$ is $8 \mathrm{~mm}$ to $10 \mathrm{~mm}, \theta$ is $-45^{\circ}$ to $45^{\circ}$, and $v$ is $2 \mathrm{~mm} / \mathrm{s}$ to $4 \mathrm{~mm} / \mathrm{s}$. Then the Eqs. (5) and (6) can be obtained.

$$
\begin{gathered}
\frac{E_{m}}{E_{e}}=\frac{\omega^{2}>>v^{2}-2 \omega r v \sin \theta}{\sqrt{v^{2}+\omega^{2} r^{2}-2 \omega r v \sin \theta}} \div \frac{U I}{v} \\
=\frac{v}{\sqrt{v^{2}+\omega^{2} r^{2}-2 \omega r v \sin \theta}} \approx \frac{v}{\omega r}
\end{gathered}
$$

According to Eq. (6), $E_{m}$ in the rotation stage is much smaller than $E_{e}$ in the sidewall stay stage. The change of the input heat in the rotation stage can be obtained by the enlarged waveform on the y-axis of Fig. 10, which is shown in Fig. 11.

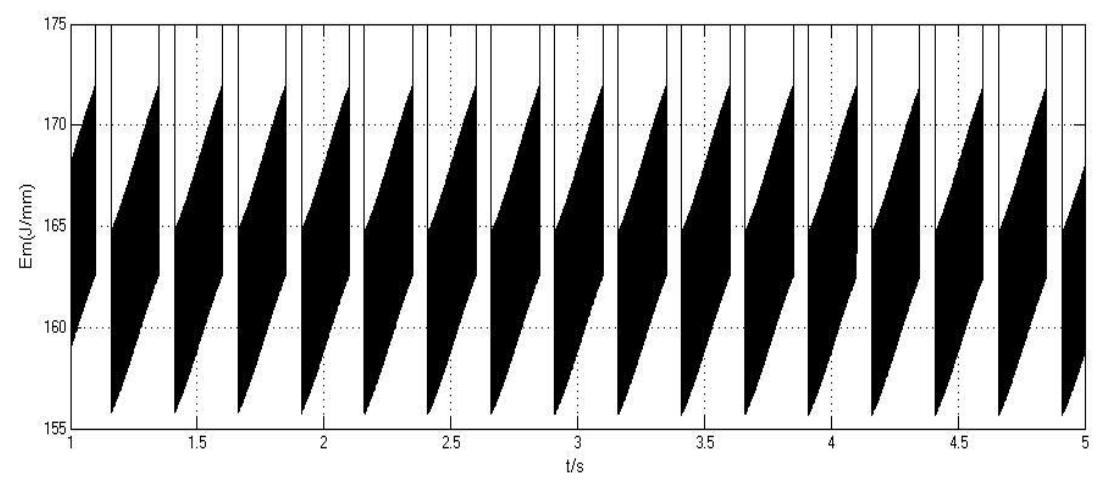

Figure 11: Enlarged waveform of $E_{m}$ in Fig. 10. 
Fig. 11 shows that the arc position does not change after the sidewall stay stage, but the heat input has a significant decrease. It's obvious that the signs $\theta$ and $\omega$ are opposite, which makes the denominator in Eq. (3) become larger and $E_{m}$ becomes smaller. Assuming that the wire feed speed increases to $7.2 \mathrm{~m} / \mathrm{min}$ in the third second, the change of $E_{m}$ is shown in Fig. 12 .

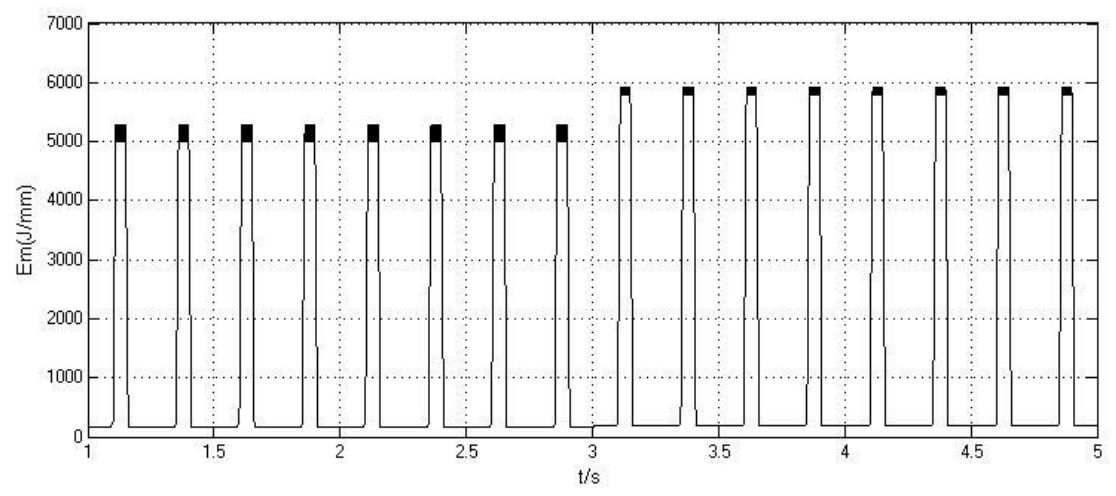

Figure 12: Waveform of $E_{m}$ when the wire feed speed increases.

As the wire feed speed increases, the wire melting speed should also be increased to ensure the stable arc length. So the welding current need to be increased and $E_{m}$ becomes larger as shown in Fig. 12. The heat input in the sidewall stay stage is significantly increased. Fig. 13 shows the enlarged waveform on the y-axis of Fig. 12, and the heat input in the rotation stage is also increased. As the deposition coefficient increases, there is more molten metal per unit weld length, which flows to the pool centre under the influence of gravity. Then the pool forms a convex after cooling under the combined effect of gravity and surface tension. So the wire feed speed should be controlled reasonable to avoid the convex weld.

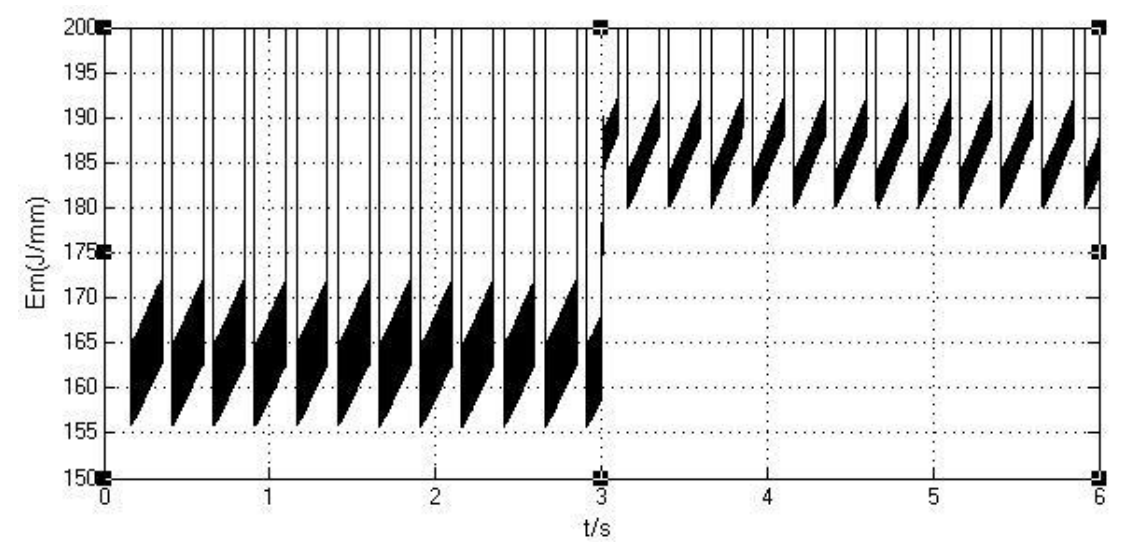

Figure 13: Enlarged waveform of $E_{m}$ in Fig. 12.

According to Eq. (6), when the gun walking speed, that is, the welding speed increases, $E_{e}$ will decrease in the sidewall stay stage. Fig. 14 shows the change of $E_{e}$ as the welding speed increases from $2 \mathrm{~mm} / \mathrm{s}$ to $4 \mathrm{~mm} / \mathrm{s}$, which will results in poor sidewall fusion. Therefore, at this time the welding speed should be reduced.

Fig. 15 shows the enlarged waveform on the y-axis of Fig. 14. It is obvious that as the welding speed changes, the heat input in the rotation stage has changed little, only the amplitude of which increases. Through Figs. 14 and 15, it can be seen that the welding speed has little effect on the heat input per unit length in the rotation stage, but has large influence on that in the sidewall stay stage. 


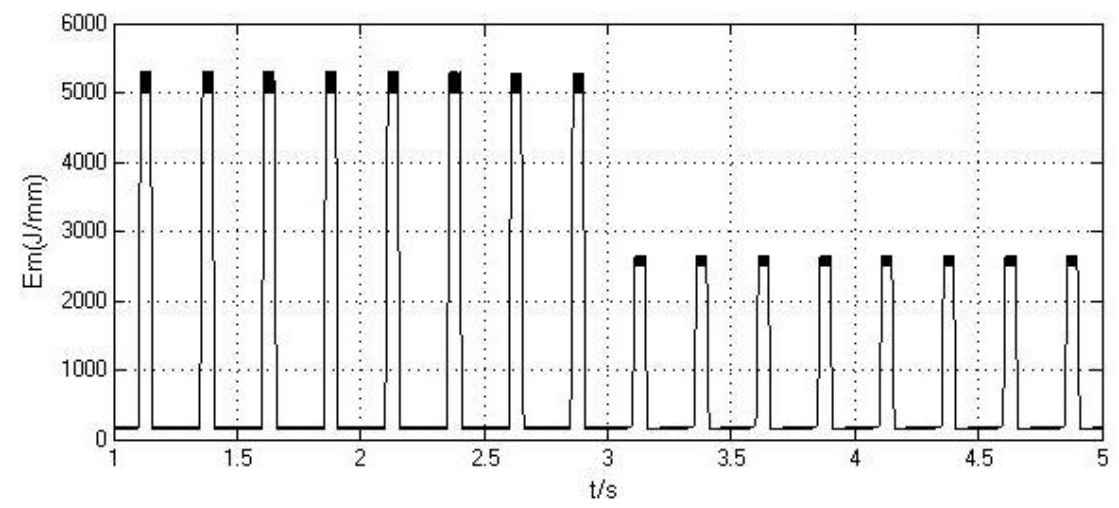

Figure 14: Waveform of $E_{m}$ when the welding speed is increased.

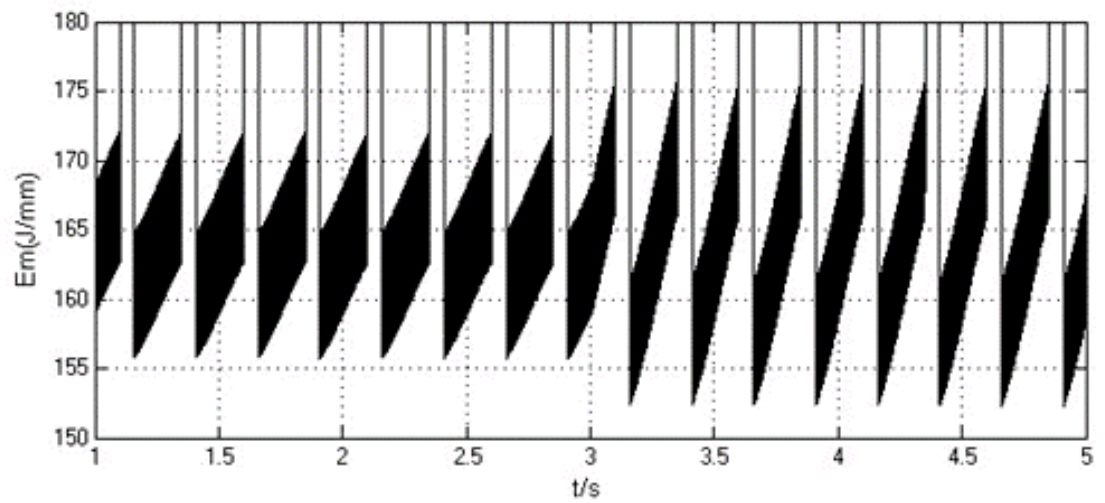

Figure 15: Enlarged waveform of $E_{m}$ in Fig. 14.

If the welding speed is very small, $E_{e}$ will be too large, which means that the heat absorbed by the sidewall is too much. The parent mental will be overheated, and the overlap is produced, which will easily cause undercut and other defects. Therefore, the reasonable welding speed choice is crucial.

\subsection{Effect of the stay time on the sidewall}

The sidewall stay time $t_{s}$ in the rotating arc NG-GMAW also has a significant effect on the welding quality. Fig. 16 shows the simulation result when the sidewall stay time changes from $50 \mathrm{~ms}$ to $200 \mathrm{~ms}$.

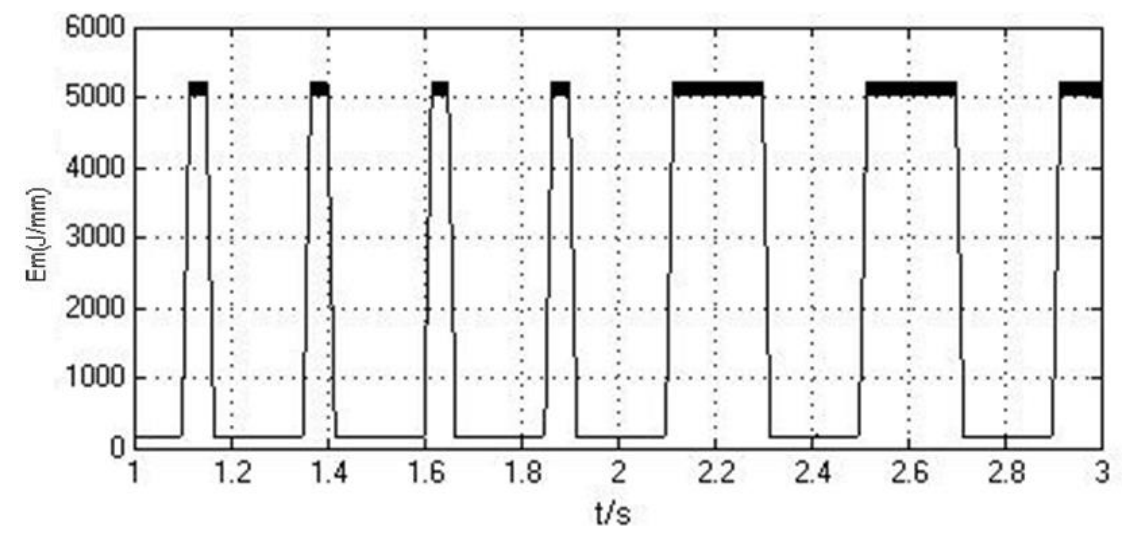

Figure 16: Waveform of $E_{m}$ during the sidewall stay time changes.

The increase of $t_{s}$ has no effect on the heat input both in the sidewall stay stage and the rotation stage, but can increase the pulse period or frequency. When $t_{s}$ is short, the frequency 
is large and the arc has strong effect of pool stirring, which will help to shape the middle part of the weld bead. However, the sidewall stay time is short to lead to the unstable sidewall fusion. As $t_{s}$ increases, the sidewall melting and penetration tends to be stable. If $t_{s}$ continues to increase, the arc stirring effect decreases and the pool cools too fast to limit the exhaust and slag, which will easily produce welding defects of gas pore and slag inclusion.

\section{CONCLUSION}

Simulation and analysis results show that increased rotation angular velocity $\omega$ helps to avoid the overlap defect, but the effect of the wire feed speed change is exactly the opposite. Too large rotation angular amplitude can easily cause the arc climb on the sidewall and uneven sidewall fusion. However, too small rotation angular amplitude may cause the overlap and poor weld formation. Moreover, too large welding speed is not conductive to promote the sidewall melt and increase the sidewall penetration, which can cause poor sidewall fusion. Too large sidewall stay time can cause the incomplete fusion of the other side to produce the gas pore and slag inclusion defects.

All the results illustrate a flexible and efficient method provided for the analysis and optimization of NG-GMAW welding process parameters to discover new phenomena, improve efficiency and save cost.

\section{ACKNOWLEDGEMENTS}

This paper was supported by the National Natural Science Foundation of China (No. 61473172) and Young Scholars Program of Shandong University (2017WLJH26), which are gratefully acknowledged.

\section{REFERENCES}

[1] Dittrich, D.; Schedewy, R.; Brenner, B.; Standfuß, J. (2013). Laser-multi-pass-narrow-gapwelding of hot crack sensitive thick plates, Physics Procedia, Vol. 41, 225-233, doi:10.1016/j.phpro.2013.03.073

[2] Yu, Y. C.; Yang, S. L.; Yin, Y.; Wang, C. M.; Hu, X. Y.; Meng, X. X.; Yu, S. F. (2013). Multipass laser welding of thick plate with filler wire by using a narrow gap joint configuration, Journal of Mechanical Science and Technology, Vol. 27, No. 7, 2125-2131, doi:10.1007/s12206$\underline{013-0525-9}$

[3] Li, R.; Wang, T.; Wang, C.; Yan, F.; Shao, X.; Hu, X.; Li, J. (2014). A study of narrow gap laser welding for thick plates using the multi-layer and multi-pass method, Optics \& Laser Technology, Vol. 64, 172-183, doi:10.1016/j.optlastec.2014.04.015

[4] Cai, X. Y.; Fan, C. L.; Lin, S. B.; Yang, C. L.; Bai, J. Y. (2016). Molten pool behaviors and weld forming characteristics of all-position tandem narrow gap GMAW, International Journal of Advanced Manufacturing Technology, Vol. 87, No. 5-8, 2437-2444, doi:10.1007/s00170-016$\underline{8644-y}$

[5] Elmesalamy, A.; Francis, J. A.; Li, L. (2014). A comparison of residual stresses in multi pass narrow gap laser welds and gas-tungsten arc welds in AISI 316L stainless steel, International Journal of Pressure Vessels and Piping, Vol. 113, 49-59, doi:10.1016/j.ijpvp.2013.11.002

[6] He, Y.; Tang, X. H.; Zhu, C. X.; Lu, F. G.; Cui, H. C. (2017). Study on insufficient fusion of NGGMAW for $5083 \mathrm{Al}$ alloy, International Journal of Advanced Manufacturing Technology, Vol. 92, No. 9-12, 4303-4313, doi:10.1007/s00170-017-0485-9

[7] Xu, H. L.; Liu, W.; Lu, F. G.; Wang, P.; Ding, Y. M. (2017). Evolution of carbides and its characterization in HAZ during NG-TIG welding of Alloy 617B, Materials Characterization, Vol. 130, 270-277, doi:10.1016/j.matchar.2017.06.021

[8] Liu, W. J.; Li, L. Y.; Yue, J. F.; Yan, P. Y.; Liu, X. H. (2017). Research on the "jump sidewall" behavior and its signal characteristics in narrow gap P-MAG welding, International Journal of 
Advanced Manufacturing Technology, Vol. 91, No. 1-4, 1189-1196, doi:10.1007/s00170-0169796-5

[9] Phaoniam, R.; Shinozaki, K.; Yamamoto, M.; Kadoi, K.; Nishijima, A.; Yamamoto, M. (2014). Solidification cracking susceptibility of modified 9Cr1Mo steel weld metal during hot-wire laser welding with a narrow gap groove, Welding in the World, Vol. 58, No. 4, 469-476, doi: 10.1007/s40194-014-0130-2

[10] Kim, J.-S.; Yi, H.-J. (2017). Characteristics of GMAW narrow gap welding on the armor steel of combat vehicles, Applied Sciences, Vol. 7, No. 7, Paper 658, 13 pages, doi:10.3390/app7070658

[11] Guo, N.; Wang, M.; Guo, W.; Yu, J.; Feng, J. (2014). Study on forming mechanism of appearance defects in rotating arc narrow gap horizontal GMAW, International Journal of Advanced Manufacturing Technology, Vol. 75, No. 1-4, 15-20, doi:10.1007/s00170-014-6127-6

[12] Xu, W. H.; Lin, S. B.; Fan, C. L.; Yang, C. L. (2015). Prediction and optimization of weld bead geometry in oscillating arc narrow gap all-position GMA welding, International Journal of Advanced Manufacturing Technology, Vol. 79, No. 1-4, 183-196, doi:10.1007/s00170-015-6818$\underline{7}$

[13] Shi, H.; Zhang, K.; Xu, Z.; Huang, T.; Fan, L.; Bao, W. (2014). Applying statistical models optimize the process of multi-pass narrow-gap laser welding with filler wire, International Journal of Advanced Manufacturing Technology, Vol. 75, No. 1-4, 279-291, doi:10.1007/s00170014-6159-y

[14] Li, W.; Gao, K.; Wu, J.; Wang, J.; Ji, Y. (2015). Groove sidewall penetration modeling for rotating arc narrow gap MAG welding, International Journal of Advanced Manufacturing Technology, Vol. 78, No. 1-4, 573-581, doi:10.1007/s00170-014-6678-6

[15] Rathod, D. W.; Francis, J. A.; Roy, M. J.; Obasi, G.; Irvine, N. M. (2017). Thermal cycledependent metallurgical variations and their effects on the through-thickness mechanical properties in thick section narrow-gap welds, Materials Science and Engineering: A, Vol. 707, 399-411, doi:10.1016/j.msea.2017.09.044 